\title{
Nonequilibrium structural states in nickel after large plastic deformation
}

\author{
I. A. Ditenberg ${ }^{1,2 \dagger}$, E. A. Korznikova ${ }^{3 \ddagger}$, A. N. Tyumentsev ${ }^{1,2,4}$, D. Setman ${ }^{5}$, M. Kerber ${ }^{5}$, \\ M. J.Zehetbauer ${ }^{5}$

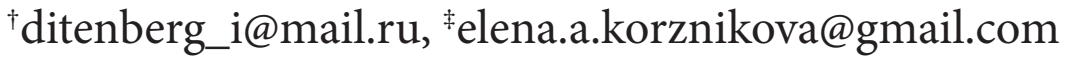

\begin{abstract}
${ }^{1}$ The Institute of Strength Physics and Materials Science of the Siberian Branch of RAS, Akademicheskii pr. 2/4, 634021, Tomsk, Russia

${ }^{2}$ The Siberian Physical-Technical Institute, Novosobornaya pl. 1, 634050, Tomsk, Russia

${ }^{3}$ The Institute of Metals Superplasticity Problems RAS, Khalturin st. 39, 450001, Ufa, Russia

${ }^{4}$ Tomsk State University, Lenin pr. 36, 634050, Tomsk, Russia

${ }^{5}$ Research Group Physics of Nanostructured Materials, Faculty of Physics, University of Vienna, Boltzmanngasse 5, A-1090, Wien, Austria

Using the methods of structural characterization and measuring the parameters of thermophysical properties, we have studied the features of highly nonequilibrium structural states that form in pure nickel in the course of high pressure torsion in Bridgman's anvils.
\end{abstract}

Keywords: high pressure torsion, nickel, microstructure, high-defect states, point defects.

\section{Introduction}

By the present time perceptions have been formed that among the basic factors that are responsible for formation of a set of unusual physical and mechanical properties in submicrocrystalline and nanostructural materials, of key importance are the features of their highly nonequilibrium structure. Of special significance here are defect substructures of grain boundaries that are distinguished by high defect density, structural and thermodynamic nonequilibrium, the presence of considerable fields of local internal stresses, a change of the atomic density in near-boundary zones, etc. [1-4, etc.]. Unfortunately, in spite of a large amount of experimental data, detailed characterization of such structural states is performed only in isolated works. In particular, it has been demonstrated in the works [4-10] that an important characteristic of highly defect states in metallic materials are substructures with high values of the crystal lattice curvature, whose permanent "companions» are grain boundaries with variable misorientation vectors $\left(\partial \theta / \partial r \approx \chi_{i j}\right)$ or pile-ups of continuously distributed partial disclinations. It is assumed that such states can be characterized by a high density of point defects.

In the present work a study has been conducted on the features of highly nonequilibrium structural states that are formed in pure nickel in the course of plastic deformation via high pressure torsion in Bridgman's anvils.

\section{Experimental material and procedures}

The initial nickel samples of high (99.998\%) purity in the shape of disks with a diameter of $8 \mathrm{~mm}$ and thickness $h=0.8 \mathrm{~mm}$ (after deformation $h_{\mathrm{K}} \approx 0.6 \mathrm{~mm}$ ) were in a structural state with a mean grain size of around $6 \mu \mathrm{m}$. The samples were subjected to deformation by torsion under the pressure $\mathrm{P} \approx 4 \mathrm{GPa}$ at room temperature to various strains determined by the number of disk revolutions $(N)=0.1,0.5,1,2$ and 5 .

The features of thermophysical processes of bulk samples were studied using the method of differential scanning calorimetry (DSC) on a Perkin Elmer DSC7 device. Defect density was determined from the residual electrical resistivity of the deformed samples after isochronal annealings. The studies were performed in the temperature range from $50^{\circ} \mathrm{C}$ to $350^{\circ} \mathrm{C}$, with a step of $25^{\circ} \mathrm{C}$ and duration of annealings at each step $10 \mathrm{~min}$.

Electron-microscopy study of thin foils prepared from sections parallel and perpendicular to the anvil plane was conducted on a Philips CM-30 TWIN electron microscope at an accelerating voltage of $300 \mathrm{kV}$. Foils in the section parallel to the anvil plane were prepared by electropolishing in the solution $90 \% \mathrm{C}_{4} \mathrm{H}_{9} \mathrm{OH}+10 \% \mathrm{HClO}_{4}$ on a Struers Tenupol device at a voltage of 35-40 V. To obtain thin foils in the sections normal to the anvil plane, a copper layer with a thickness of $\approx 3 \mathrm{~mm}$ was electrodeposited on samples with a size of $5 \times 2 \times 0.15 \mathrm{~mm}$. Flat samples in the above-indicated sections were cut on an electrospark discharge machine and mechanically ground to the thickness $\approx 100 \mu \mathrm{m}$. Further thinning was achieved by way of argon ion sputtering at an accelerating voltage of $5 \mathrm{kV}$.

Study of the features of the defect structure of grain bulk and grain boundaries was conducted using the techniques of dark-field analysis of high continuous and discrete misorientations [4-9] which allow to define quantitatively the typical sizes of grain-subgrain structure and the parameters of crystal lattice curvature. 


\section{Results}

Figure 1 presents an example of a calorimetric curve for heating of a sample strained at $N=2$. As can be seen, two exothermic peaks in the temperature ranges $100-180^{\circ} \mathrm{C}$ and 200-320 ${ }^{\circ} \mathrm{C}$ are observed. The peak at $120^{\circ} \mathrm{C}$ corresponds to an insignificant heat generation. As established earlier [11], in the course of quenching experiments in this temperature range in pure nickel annealing of vacancies takes place, hence this peak will be subsequently referred to as the vacancy peak.

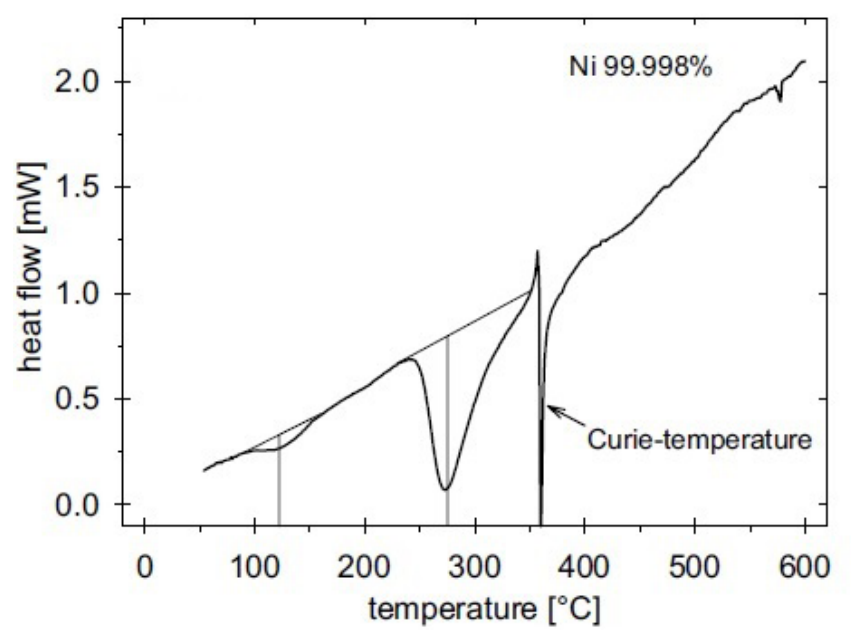

Fig. 1. Dependence of heat flow on heating temperature of Ni strained at $N=2(\gamma=47.6)[12]$.
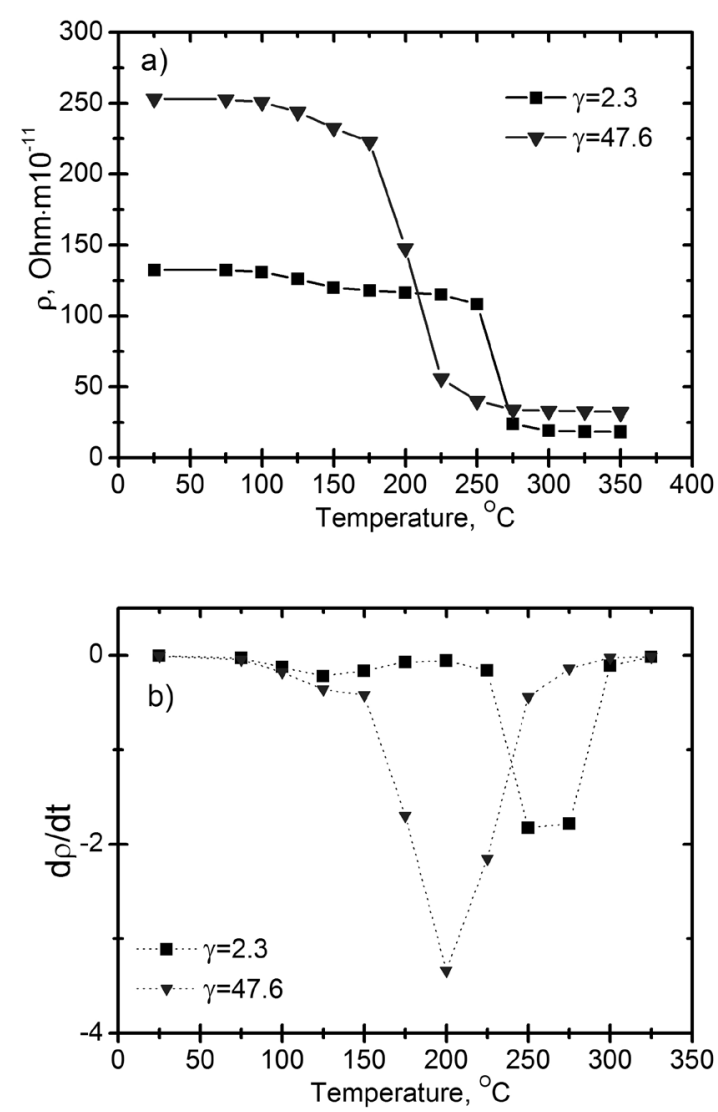

Fig. 2. Examples of dependencies of specific electrical resistance on annealing temperature (a) and the temperature gradient of electrical resistivity (b) of strained $\mathrm{Ni}$.
At temperatures above $180{ }^{\circ} \mathrm{C}$ a sharp decline in heat flow (fig.1) is observed, which is related to initiation of structural transformations via annihilation of dislocations and activation of recrystallization processes. The maximum values of generated heat are characterized by a peak at the temperature $\approx 220^{\circ} \mathrm{C}$.

In the temperature range $250-300{ }^{\circ} \mathrm{C}$ the peak becomes more flat, which is indicative of a less intensive heat generation. Thus in the given temperature range thermally-activated structural transformations evidently become completed. Exotermic peak at $358^{\circ} \mathrm{C}$ corresponds to the Curie point.

During further temperature increase no significant heat effects were discovered.

It is typical for samples after large and small plastic strains that the change in residual electrical resistivity has the shape of a common S-curve, as shown in fig. 2 a. With a view to separate the contributions of vacancies and dislocations, we have differentiated $(\mathrm{dp} / \mathrm{dt})$ the dependence of residual electrical resistivity on annealing temperature $\Delta \rho\left(\mathrm{T}_{\mathrm{ann}}\right)$ (fig.2b).

On the produced curve (fig.2b) in the case of small strains $(\gamma=2.3) 2$ peaks are observed. The peak at $125{ }^{\circ} \mathrm{C}$ corresponds to the temperature of the vacancy peak on the DSC curve (fig.1). Based on this, it is assumed that the modulated decrease of electrical resistivity in the temperature range $100-150{ }^{\circ} \mathrm{C}$ correlates with annealing of mono- and bivacancies $(\gamma=2.3$, fig.2b). The temperature of the second peak is close to the temperature of dislocations annealing. As strain increases ( $\gamma=47.6$, fig.2b), an increase in stored energy of defects and growth of the moving force of recrystallization facilitate displacement of the dislocation peak towards low temperatures and, in fact, its merging with the vacancy peak. The sharp decline in the temperature range $150-200{ }^{\circ} \mathrm{C}$ corresponds to annealing of dislocations.

The results of DSC and the data from measurement of residual electrical resistivity indicate completion of structural transformations at the temperature $\approx 300{ }^{\circ} \mathrm{C}$.

The results of investigation into the thermophysical properties of nickel in a wider range of strains is presented in the paper [12].

The above-indicated features of structural changes can be visibly illustrated by micrographs showing the structural states of strained nickel after the corresponding heat treatments (fig.3).

After annealing at $125{ }^{\circ} \mathrm{C}$ the microstructure (fig.3a) practically does not differ from the microstructure which is observed immediately after straining [7]. It has been established that a structural transformation begins at a temperature above $175^{\circ} \mathrm{C}$. After $225^{\circ} \mathrm{C}$ the features of the microstructure indicate activation of the initial recrystallization processes (fig.3b) which are actually completed at $250{ }^{\circ} \mathrm{C}$ (fig.3c). At a temperature of $250{ }^{\circ} \mathrm{C}$ an intensive progress of the processes of accumulative recrystallization is observed, as a result of which the microstructure is represented by practically defectfree grains of micron $(4-7 \mu \mathrm{m})$ sizes (fig.3d).

\section{Discussion}

It follows from the above-presented results and the data from the works $[7,13]$ that the structural states immediately after a large plastic deformation and prior to the 

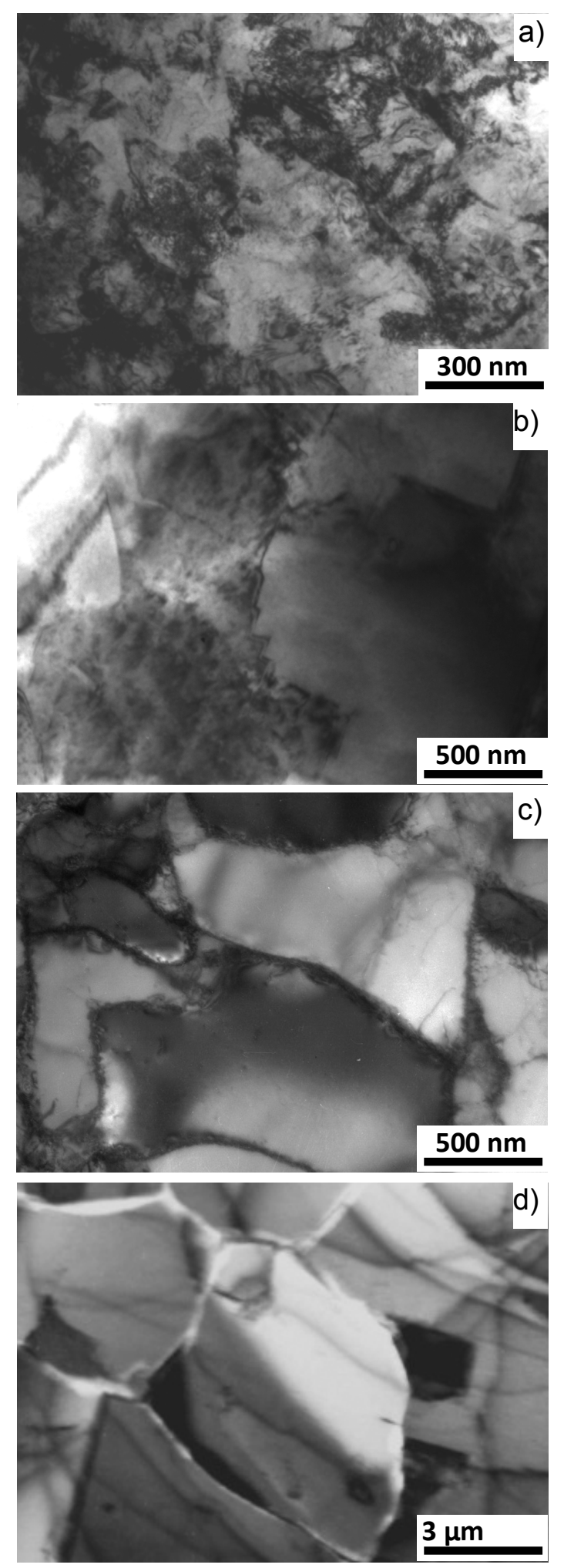

Fig. 3. Bright-field electron-microscopy images of the structure of strained $(N=2)$ nickel after annealings at the temperatures $125^{\circ} \mathrm{C}(\mathrm{a}), 225^{\circ} \mathrm{C}(\mathrm{b}), 250^{\circ} \mathrm{C}$ (c), $300^{\circ} \mathrm{C}(\mathrm{d})$.

temperature of start of active relaxation processes are highly defect (highly nonequilibrium) states.

It was established earlier [7, 13-15], during study of microstuctural and defect structure features in nickel subjected to large plastic deformation, that for such structural states it was typical to have substructures with high
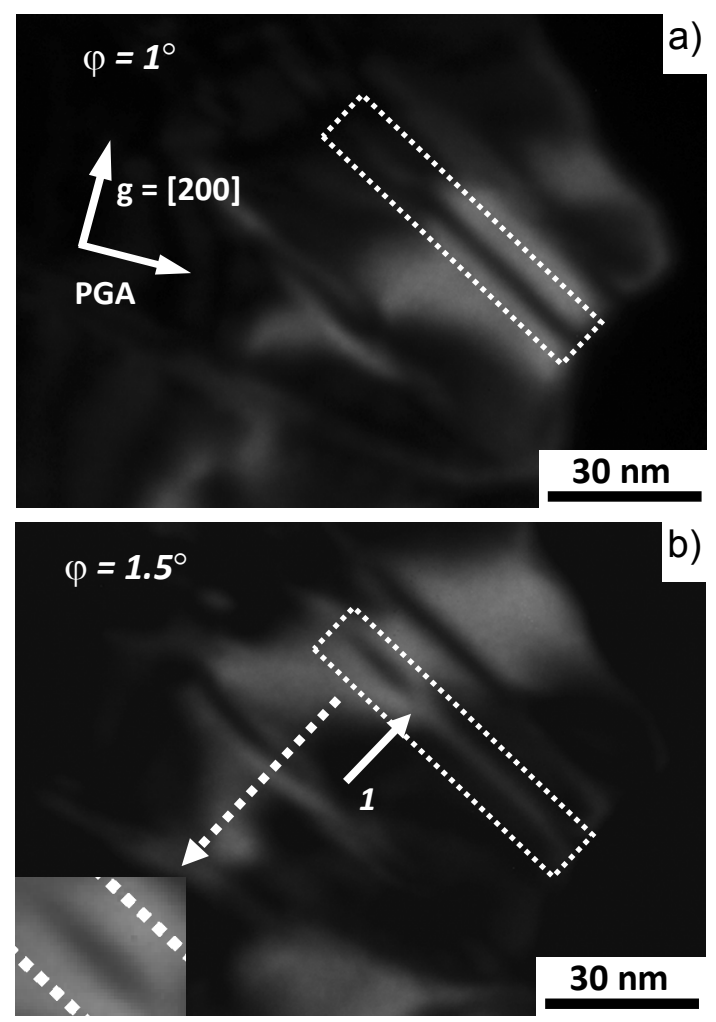

Fig. 4. Nanobands of reorientation in a submicrocrystal of nickel after severe plastic deformation via high pressure torsion $[7,12]$. (a, b) Dark-filed images at different inclination angles $(\varphi)$ of the goniometer.

values of the crystal lattice curvature and a high density of boundaries with variable misorientation vectors.

In particular, inside submicrograins nano-twins and nano-bands of reorientation were found. An example of dark-field images of the latter is shown in fig.4.

These defects represent pairs of broken off misorientation boundaries of opposite signs, whose movement realizes a shift with reorientation of the crystal lattice and leaves behind nanobands with a length of up to tens of nanometers and a width of several nanometers, misoriented to small $\left(\sim 0.5-1^{\circ}\right)$ angles. In the works $[8,16]$ there was conducted a detailed study of these structural states, in the process of which it was established that the values of the crystal lattice curvature in them reached over $300 \mathrm{deg} / \mu \mathrm{m}$ at extremely small (around 3 $\mathrm{nm}$ ) spatial scales of their finding. Note should be made that this is an order of magnitude higher than in submicrocrystals with sizes of several tenths of micron [7].

An important moment is the fact that in the framework of the dislocation model of elastic-plastic curvature of the crystal lattice $[8,9]$, in accordance with the formula $\left(\rho_{ \pm}=\rho_{-}-\rho_{+}=\chi_{\mathrm{ij}} /|\mathbf{b}|\right)$, at the above-indicated values $\chi_{\mathrm{ii}} \approx(200-300)^{\circ} \mu \mathrm{m}^{-1}$, the density of geometrically necessary dislocations required for its formation is $\rho_{ \pm} \approx(1-1.5) \times 10^{12} \mathrm{~cm}^{-2}$. The distances between the dislocations amount to around 10 $\mathrm{nm}$, i.e. 2-3 times larger than the width of the revealed nanobands. This estimate, as well as the absence, in the zones of nanobands and in the grain itself, of any signs of dislocation contrast, indicate non-applicability of the dislocation model of continuous misorientations [16], and consequently, that the extraordinarily high (hundreds of degrees $/ \mu \mathrm{m}$ ) curvature 
of the crystal lattice found in the vicinity of nanodipoles of partial disclinations is elastic.

In our opinion, the processes of formation and relaxation of such nonequilibrium substructures by way of division of dislocation ensembles into two subsystems of dislocations of opposite signs seem impossible.

According to perceptions $[9,16,17]$, formation of such states is possible in the framework of the model of crystal lattice reorientation via quasi-viscous flow by flows of nonequilibrium (generated during plastic straining) point defects in fields of high local pressure gradients. Correspondingly, the above-described highly nonequilibrium structural states are characterized by a high density of point defects. The conducted theoretical estimates [17] and experimental results [1213,19 ] indicate a high (up to $c_{v} \approx 10^{-4}$ ) concentration of nonequilibrium vacancies in such states, including those resulting from large plastic strains. Unfortunately, there are no literature data about the concentration of interstitial atoms in such substructures known to us.

The estimates we conducted in the works $[16,17]$ showed that at the above-indicated concentrations of nonequilibrium vacancies, the quasi-viscous mechanism of crystal lattice reorientation was capable to ensure formation and relaxation of highly nonequilibrium structures in rather wide ranges of temperatures and strains of plastic deformation.

\section{Conclusions}

Based on comparison of the results of electron-microscopy analysis and parameters of thermophysical properties of nicked after deformation via high pressure torsion, we have put forward an assumption that nonequilibrium substructural states are characterized by a high concentration of nonequilibrium vacancies which ensure realization of the quasi-viscous mechanism of formation and relaxation of submicro- and nanocrystalline structural states.

Microstructural investigations were performed using the equipment of the Tomsk Materials Science Center of Common Use of the Tomsk State University.

\section{References}

1. R.Z. Valiev, R.S. Musalinov. The Physics of Metals and Metallography. 78 (6), 114 (1994).

2. Z. Horita, D. J. Smith, M. Furukawa, M. Nemoto, R.Z. Valiev, T.G. Langdon. Mat. Sci. Forum. A204-206, 437 (1996).
3. Yu. A. Babanov, L.A. Blaginina, I. V. Golovshchikova, T. Haubold, F. Boscherini, S. Mobilio. The Physics of Metals and Metallography. 83(4), 444 (1997).

4. A.N. Tyumentsev, Yu.P. Pinzhin, A.D. Korotaev, M. V. Tret'yak, R. K. Islamgaliev, R.Z. Valiev. The Physics of Metals and Metallography. 86(6), 604 (1998).

5. A. N. Tyumentsev, A. D. Korotaev, Yu. P. Pinzhin. Physical Mesomechanics. 7(3-4), 31 (2004).

6. A. N. Tyumentsev. American Institute of Physics. 999, 268 (2008).

7. I.A. Ditenberg, A.N. Tyumentsev, A.V. Korznikov, E. A. Korznikova. Physical Mesomechanics. 16(3), 239 (2013).

8. A.N. Tyumentsev, I. A. Ditenberg. Russian Physics Journal. 54(9), 977 (2012).

9. A.N. Tyumentsev, I.A. Ditenberg, A.D. Korotaev, K. I. Denisov. Physical Mesomechanics. 16(4), 319 (2013).

10. M. Kamaya. Ultramicroscopy. 111(8), 1189 (2011).

11. E. Schafler, G. Steiner, E. Korznikova, M.B. Kerber, M. J. Zehetbauer. Mat. Sci. Eng. A. 410-411(5), 169 (2005).

12. D. Setman, E. Schafler, E. Korznikova, M. J. Zehetbauer. Mat. Sci. Eng. A 493, 116 (2008).

13. E. A. Korznikova, I. A. Ditenberg, A.N. Tyumentsev, A. V. Korznikov. Deformation and Fracture of Materials. 11, 8 (2010). (in Russian)

14. E. A. Korznikova, S.Y. Mironov, A. V. Korznikov, A. P. Zhilyaev, T. G. Langdon. Mat. Sci. Eng. A. 556, 437 (2012).

15. E. A. Korznikova, M. Zehetbauer. Materialovedenie 6, 39 (2008). (in Russian)

16. A.N. Tyumentsev, I.A. Ditenberg. Phys. Mesomech. 14(5-6), 249 (2011).

17. A.N. Tyumentsev, I.A. Ditenberg, K.I. Denisov, E. A. Korznikova, A. V. Korznikov, V. M. Chernov. Russian Physics Journal. 53(12), 1295 (2011).

18. V.A. Starenchenko, D. N. Cherepanov, Y. V. Solov'eva, L. E. Popov. Russian Physics Journal. 52(4), 398 (2009).

19. M. J. Zehetbauer, G. Steiner, E. Schafler, A. Korznikov, E. Korznikova. Mat. Sci. Forum. 503-504, 57 (2006). 